\title{
Dissertando Mariana para entender o Brasil: historiografia regional e História econômica de Minas Gerais após o augie da mineração
}

\author{
Leandro Braga de Andrade
}

Introdução

Os estudos regionais ganharam maior força na historiografia brasileira quando também se processou o questionamento de grandes paradigmas explicativos que, ao serem testados nas particularidades empíricas, nem sempre se mostraram suficientes. Essa realidade se manifestou, inclusive, na segmentação dos campos do conhecimento, onde abordagens e temas novos como cotidiano, gênero, etnia, entre tantas outras, se uniram aos estudos regionais, no processo de expansão dos estudos históricos.

A História Regional, em seus diversos matizes, conseguiu abarcar tais mudanças, alimentada, sobretudo, pela disseminação de Programas de Pós-Graduação em todo o Brasil. A recuperação e preservação de acervos locais foram, dessa forma, incentivadas, ao passo que novos pesquisadores viam a possibilidade de penetrar em grandes discussões da historiografia, tendo como objeto de análise a realidade local. $^{2}$

${ }^{1}$ Doutorando do Programa de Pós-Graduação em História Social da Universidade Federal do Rio de Janeiro. Mestre em História, pela Universidade Federal de Minas Gerais.

${ }^{2}$ Uma boa apresentação da problemática teórico-metodológica e da expansão da História Regional no Brasil está na coletânea República em Migalhas, editada em 1990. SILVA, Marco A. (coord). República em Migalhas: História Regional e Local. São Paulo. Marco Zero. 1990. 
Uma das áreas que mais ganharam reforço pela abordagem regional, em termos de interpretação da História do Brasil, foi a História Econômica. O caso que apresentaremos aqui é emblemático, nesse sentido. Os estudos sobre Mariana marcaram contribuição fundamental para o entendimento de Minas Gerais no pós-auge da mineração, influenciando de maneira decisiva as interpretações a respeito da dinâmica econômica escravista colonial e imperial.

A cidade de Mariana é um dos mais antigos núcleos de povoamento de Minas Gerais. Desde o final do século XVII ali começara a se formar, em torno da extração aurífera, uma das mais tradicionais e famosas cidades coloniais mineiras. A criação da Vila do Carmo, em 1711, nome também do rio que a corta, fez com que dezenas de povoados surgidos na região central de Minas se tornassem distritos e freguesias pertencentes, formando um imenso Termo administrativo. Foi também a primeira vila elevada à cidade, em 1745, passando a se chamar Mariana, além de sede do primeiro bispado da Capitania de Minas Gerais. ${ }^{3}$ Mas, para além das efemérides que marcam este importante momento da história da América Portuguesa, que foi a descoberta do ouro, a colonização e o povoamento do interior, Mariana tem sido também um privilegiado laboratório de análises para a historiografia. De abordagens regionais, nasceram significativas contribuições para o debate que se prolonga, ainda hoje, com notável vigor, em torno da história econômica do Brasil.

Nos últimos 20 anos, acompanhando as transformações anteriores na historiografia brasileira, muitas pesquisas têm optado por abordar espaços mais circunscritos, entre outros motivos, para não cair em generalizações, comuns nas teses memorialistas ou tradicionais, que abordavam toda a Capitania ou Província de Minas Gerais. Além disso, a própria expansão temática e teórica da historiografia encontrou terreno fértil em uma grande delimitação administrativa, com características sociais e econômicas diversas.

\footnotetext{
${ }^{3}$ BARBOSA, Waldemar A. Dicionário Histórico Geográfico de Minas Gerais. Belo Horizonte. Ed. Sterb. 1971. 
Soma-se a isso o fato de a cidade de Mariana ter preservado um grande, variado e raro acervo documental referente aos séculos XVIII e XIX, e também o fato de existir, na cidade, um curso de graduação em História, ofertado pela Universidade Federal de Ouro Preto, desde 1979. ${ }^{4}$

O acesso direto ao material empírico unido à efervescência do debate acadêmico fez germinar iniciativas de pesquisas que se desdobraram em dezenas de dissertações e teses, em diversos Programas de Pós-Graduação do Brasil. Optamos por analisar seis dissertações de mestrado que tiveram, no campo da história econômica, algumas influências e preocupações em comum: versavam ou foram tributárias de um caloroso debate da historiografia dos anos de 1980 e 1990 sobre a economia mineira no pós-auge da mineração. Além disso, tiveram Mariana como objeto de análise que, como antigo núcleo minerador, também fora alvo do referido debate. $^{5}$

Mas antes de analisarmos e mesmo mencionarmos as pesquisas sobre as quais nos debruçamos é necessário entender qual foi o grande debate da historiografia econômica do Brasil colonial, e como as pesquisas, principalmente sobre o século XIX mineiro, interferiram com seu revisionismo. Daí então, nascia uma abertura historiográfica, para os temas posteriormente estudados.

Muitas pesquisas alternavam-se entre "determinações externas", que ditariam os fluxos econômicos e o viver em colônia, e "determinações internas", que responderiam por relativa autonomia do movimento da economia local. Este debate alcançou o século XIX, e, portanto, a fase nacional da história do Brasil, em parte pela querela que se travou na historiografia sobre Minas Gerais.

${ }^{4}$ A abertura do curso de Mestrado em História na Universidade Federal de Ouro Preto é de 2007.

${ }^{5}$ Chegamos ao número de 6 trabalhos ao excluirmos todas as pesquisas em história econômica que abordavam exclusivamente o período de expansão e auge da extração aurífera, na primeira metade do século XVIII. A triagem foi feita em banco de teses de 5 Universidades, nos estados de Minas Gerais, São Paulo e Rio de Janeiro. 


\section{Minas Gerais no século XIX e o debate colonial}

Quando a história econômica do Brasil era dividida em ciclos produtivos, que justificavam a razão de ser da colonização portuguesa e, posteriormente a continuada dependência do país em relação ao capitalismo europeu, a paisagem que emergia era de uma sociedade dividida entre grandes senhores e seus escravos, vivendo em plantations dedicadas ao mercado externo. Minas Gerais teria um lugar especial nesse modelo, por representar a exploração do ouro e a conformação de nova forma de ocupação, com uma incipiente urbanização. O pomposo capítulo da mineração, no século XVIII, e todo o complexo social que ele engendrou ofuscavam outros aspectos da vida econômica e social, assim como outros períodos da história da região, que depois se mostraram tão importantes quanto o primeiro para o entendimento da história do Brasil.

É dispensável aqui refazer todo o itinerário da historiografia que desmitificou a sociedade mineradora, que de gloriosa e até democrática passou a expropriada, pobre e finalmente vista como um complexo e diversificado sistema econômico-social, mas que também gerava riqueza interna, mesmo que de forma tão desigual. Por outro lado, é importante tocar em alguns pontos que influenciaram pesquisas posteriores.

Nas décadas de 1970 e 1980 processou-se no Brasil uma grande revisão da historiografia, em especial das teses explicativas para a colonização. Questões como a economia de abastecimento, as críticas à coisificação do escravo e uma nova visão sobre as populações livres pobres, foram abordadas à luz da influência da Escola dos Annales e da História Social Inglesa. Essas pesquisas traziam a marca da exigência de um forte embasamento empírico e métodos refinados de análise. Entre tais estavam a quantificação, séries econômicas e demográficas, capazes de testar hipóteses que se opunham às clássicas interpretações já mencionadas. Nesse bojo, a história econômica e a história do trabalho escravo 
em Minas Gerais foram fundamentais para as revisões que se processaram.

As teses tradicionais sobre o ciclo do ouro, no século XVIII, viam em Minas Gerais a realização plena da vocação exportadora da economia brasileira e ainda, uma relativa democratização do acesso à riqueza e expansão da vida urbana. Já o periodo seguinte ao esvaziamento dos veios auríferos, conforme aponta Júnia Furtado, “(...) seria marcado pela ruralização da região, pela endogenia de uma economia agrícola não exportadora, voltada para o mercado interno, simbolizando a idade das trevas mineira." 6

Curiosamente foram as pesquisas sobre o século XIX que demonstraram a diversidade da ocupação, das atividades produtivas, da vida social e da possibilidade de aplicação do trabalho escravo em economias não exportadoras. Assim, o século XIX mineiro foi colocado no "mapa da História" e trouxe consigo todas as formas de ocupação, produção e relações sociais, neste ou em outros períodos e regiões do Brasil, antes relegados à condição de objeto menor.

Os trabalhos de Alcir Lenharo, Roberto Martins, Robert Slenes e Douglas Libby observaram dinamismo, diversificação, circulação e apego ao trabalho escravo de uma economia que, passado o auge da extração aurífera, se caracterizava predominantemente pela produção e comércio de gêneros alimentícios, além de um crescente setor de transformação, todos voltados para o comércio interno. No conjunto, são essas as contribuições das pesquisas desses autores, os considerados clássicos da historiografia mineira que, no entanto, guardam significativas diferenças entre suas teses. Alcir Lenharo destacou o sul de Minas Gerais como o grande celeiro de abastecimento da Corte nas primeiras décadas do século XIX, emergindo na província uma elite mercantil que participava e interferia nos rumos da construção do Estado. ${ }^{7}$ Roberto Martins, em tese que marcou os estudos

${ }^{6}$ FURTADO, Júnia F. "Novas tendências da historiografia de Minas Gerais no periodo colonial". História da historiografia. Número 02, março de 2009. p. 117.

${ }^{7}$ LENHARO, Alcir. As tropas da moderação. O abastecimento da Corte na formação política do Brasil - 1808-1842. São Paulo. Ed. Símbolo. 1979. 
sobre trabalho escravo e economia no Brasil, demonstrou que Minas Gerais, uma província não-exportadora (com um comércio interno de base vicinal), era a principal importadora de mão-de-obra cativa e com maior contingente populacional mancipio. Dessa forma, o trabalho escravo não estaria necessariamente atrelado às atividades exportadoras, o que, para a historiografia tradicional, sustentava a exploração colonial e posteriormente a dependência do Brasil em relação à Europa. ${ }^{8}$ Já Robert Slenes, tratou de identificar que havia na província um complexo mercantil dinamizado pela exportação de diamantes, ouro e, sobretudo, pelo comércio longínquo dos múltiplos de porcos, o que explicaria o apego à mão-de-obra escrava, relativizando a tese de Martins. ${ }^{9} \mathrm{O}$ complexo produtivo e proto-industrial de Minas Gerais no pós-auge da mineração ganhou destaque nas pesquisas de Douglas Libby, que percebeu predominância da agropecuária mercantil em Minas Gerais, mas também, um crescente setor de transformação (siderurgia, tecelagem, fiação, entre outros) absorvido pela demanda interna. ${ }^{10}$

A partir de então, o objetivo de muitas pesquisas, cada vez mais embasadas em farto material empírico, foi o de refutar as proposições de que o declínio do ouro e dos diamantes desarticulou a sociedade e a economia mineiras, atrofiando ou mesmo eliminando as relações internas e provocando inclusive queda populacional.

Em balanço das mudanças da historiografia mineira, na série "Termo de Mariana: História e documentação", a professora Andréa Lisly Gonçalves, avaliava, em 1998, os rumos das pesquisas:

\footnotetext{
${ }^{8}$ MARTINS, Roberto. A economia escravista de Minas Gerais no século XIX. (Mimeo) CEDPLAR/UFMG.1980.

${ }^{9}$ SLENES, Robert W. A. "Os múltiplos de porcos e diamantes: Economia Escrava de Minas Gerais no século XIX”. Estudos Econômicos. São Paulo. V. 18, n. 3. p. 449- 495. Set.-dez. 1988.

${ }^{10}$ LIBBY, Douglas. Transformação e Trabalho em uma economia escravista. Minas Gerais século XIX. São Paulo. Brasiliense: 1988. 
Assuntos que, até recentemente, pouco haviam ocupado a atenção dos estudiosos, - como o sistema escravista mineiro no século XIX, as unidades produtivas rurais voltadas para a produção de gêneros para o mercado interno, a camada dos pequenos proprietários livres etc.-, foram privilegiados em abordagens que trouxeram de volta o interesse por temas e/ ou pelos métodos da História Econômica. ${ }^{11}$

Para a autora, tais abordagens contribuíam para a crítica à tese do "Antigo Sistema Colonial", na medida em que, direta ou indiretamente relativizavam o excessivo peso dado por Fernando Novais ${ }^{12}$ à exploração mercantil da metrópole sobre a colônia. Aqui estava em cheque uma espécie de devir da História do Brasil. Entender ou discordar do "sentido da colonização" e, conseqüentemente, da formação do Brasil contemporâneo, como pretendido por Caio Prado Junior, ${ }^{13}$ mobilizava os esforços das pesquisas que cada vez mais se valiam de forte embasamento empírico.

Voltando ao balanço historiográfico da professora Andréa Lisly Gonçalves, é possivel identificar em uma tese sobre o Rio de Janeiro, o marco que influenciou diretamente a inserção das pesquisas regionais no debate acerca da História Econômica do Brasil. A obra, "Homens de Grossa Aventura: acumulação e hierarquia na praça mercantil do Rio de Janeiro, 1790-1830", de João Luís Fragoso, apresentava duras críticas às interpretações da economia colonial que davam, segundo o autor, exagerada importância à acumulação de excedentes por parte da metrópole, através da exploração colonial. O autor defendeu a hipótese da formação de um "mercado interno" que produzira "acumulações endógenas" no espaço colonial, gerando uma elite econômica residente, calcada em valores aristocráticos, e, consequentemente, re-

\footnotetext{
${ }^{11}$ GONÇALVES, Andréa Lisly. "Algumas Perspectivas da Historiografia sobre Minas Gerais séculos XVIII e XIX”. In.: Termo de Mariana: História e documentação. Mariana. Imprensa Universitária da UFOP, 1998. p. 19.

${ }^{12}$ NOVAIS, Fernando Antônio. Portugal e Brasil na crise do Antigo Sistema colonial (1777/1808). São Paulo. Hucitec, 1985.

${ }^{13}$ PRADO Jr, Caio. Formação do Brasil contemporâneo. 23ª ed.1994. São Paulo. Brasiliense. 1999.
} 
produtora de uma hierarquia social excludente. ${ }^{14}$ Publicada em 1992, a obra colocou "lenha na fogueira" e os pesquisadores mineiros, há muito preocupados com o tema da crise de ouro (um produto de exportação), cerraram fileiras com a ideia de acumulação interna, a partir da circulação comercial de gêneros não-exportáveis.

Alguns desses pesquisadores, tendo acesso à documentação preservada em Mariana, formularam propostas e problemas de pesquisa fundamentais para o tema da economia mineira no pós-auge da mineração. É por este caminho que tais pesquisas também intervieram no debate sobre economia colonial.

É bom lembrar que a documentação preservada nos arquivos, cartorial, eclesiástico e camarário de Mariana referem-se a uma ampla região ao sul e a leste do território atual da cidade. Isso porque o alcance administrativo do Termo de Mariana até o século XIX era imenso e, portanto, não se resumia às antigas áreas de mineração, perpassando por antigas regiões agropecuaristas e novas áreas de fronteira.

\section{Dissertando Mariana para entender o Brasil}

Uma pesquisa pelos bancos de teses e dissertações dos Programas de Pós-Graduação permite-nos afirmar que, de fato, a documentação preservada sobre e na cidade de Mariana, foi alvo de dezenas de estudos, em vários campos do conhecimento histórico. Elegemos, no entanto, 6 dissertações que, como já adiantamos, beberam nas águas da revisão historiográfica já colocada em relevo, tinham preocupações no campo econômico e abordaram o periodo chamado aqui de pós-auge da mineração. Portanto, as décadas finais do século XVIII e o século XIX.

\footnotetext{
${ }^{14}$ FRAGOSO, João Luis R. Homens de grossa aventura: acumulação e hierarquia na praça mercantil do Rio de Janeiro, 1790-1830. Rio de janeiro. Arquivo Nacional. 1992. 
Comecemos pela dissertação de mestrado defendida por Carla Maria Carvalho de Almeida em 1994, na Universidade Federal Fluminense: "Alterações nas unidades produtivas mineiras. Mariana - 1750-1780". A pesquisadora, graduada na Universidade Federal de Ouro Preto, levantou uma série de inventários post-mortem de Mariana, entre os anos de 1750 e 1850. O longo recorte se justificava pelo objetivo de perceber o movimento da economia nos periodos de "auge minerador" (1750-1770), "acomodação evolutiva" (17801810) e por fim o da "economia mercantil de abastecimento" (1820-1850). Atestando a concomitância entre mineração e agropecuária desde o auge da extração do ouro, em meados do XVIII, Carla Almeida substitui a ideia de decadência da economia mineira por uma "rearticulação interna" ou o período de "acomodação evolutiva". Neste período estaria sendo gestada a consolidação de uma economia de abastecimento voltada para o mercado interno e que, portanto gerara possibilidades de acumulação nos espaços não-exportadores. ${ }^{15}$ Os traços sistêmicos da economia de Minas Gerais que, reparemos, apesar das mudanças conjunturais, avançam até meados do século XIX seriam: a utilização extensiva da terra, a diversificação produtiva das unidades econômicas, o constante incremento da mão-de-obra escrava e a reprodução de uma hierarquia social excludente.

Dialogando com as já citadas teses sobre economia mineira (de Alcir Lenharo, Roberto Martins, Robert Slenes e Douglas Libby), esta pesquisa se tornou uma referência para história econômica de Minas Gerais por se alinhar à tese do "mercado interno" e por criticar os modelos explicativos tradicionais da economia colonial. Vejamos que não se trata de abarcar toda Minas Gerais, tampouco a Colônia, mas preservar uma preocupação sistêmica a partir de uma região, Mariana.

Usar a documentação e o espaço do termo de Mariana para responder questões gerais também foi a preocupação

\footnotetext{
${ }^{15}$ ALMEIDA, Carla Maria de Carvalho. Alterações nas unidades produtivas mineiras. Mariana - 1750-1780. Dissertação (Mestrado em História). UFF. Niterói. 1994.
} 
de Francisco Eduardo Andrade, também graduado na Universidade Federal de Ouro Preto, em dissertação de mestrado defendida no ano de 1995, na Universidade Federal de Minas Gerais. Em "A enxada complexa: roceiros e fazendeiros em Minas Gerais na primeira metade do século XIX" ${ }^{16}$ o autor utiliza listas nominais de habitantes (anos 1821-1822) e inventários post-mortem para traçar o perfil de pequenos roceiros e de agricultores escravistas nas freguesias rurais do termo de Mariana.

A capacidade de incremento da mão-de-obra cativa e a concentração de poder e riqueza nos espaços rurais marianenses revelam que uma economia não-exportadora poderia ser dinâmica, por conta da circulação interna de mercadorias. É com esta hipótese que Francisco Andrade ataca a ideia de pouca rigidez na estratificação social da sociedade mineira, detectando concentração de riqueza entre poucos fazendeiros brancos e escravistas.

Um diálogo com as características geográficas e históricas das regiões analisadas (Furquim, Nossa Senhora dos Remédios, São Caetano, Paulo Moreira, São João Batista do Presídio, Catas Altas, todos distritos e freguesias da área rural de Mariana) diferenciou o trabalho de Francisco Andrade do de Carla Almeida, que analisou inventários de todo o termo de Mariana, sem distinguir área urbana, rural de ocupação antiga e fronteira.

Porém, os traços que unem as mencionadas pesquisas são muitos. Ambos falam da consolidação de uma economia não-exportadora na região central de Minas Gerais, no segundo quarto do século XIX, debatem com as teses tradicionais da economia colonial e do declínio da mineração e, sobretudo, corroboram, com base em material empírico,

\footnotetext{
${ }^{16}$ ANDRADE, Francisco Eduardo. A enxada complexa: Roceiros e fazendeiros em Minas Gerais na primeira metade do século XIX. Belo Horizonte. Dissertação (Mestrado em História). Faculdade de Filosofia e Ciências Humanas. UFMG. 1995. Esta dissertação deu origem ao livro publicado recentemente, pelo autor: ANDRADE, Francisco Eduardo. Entre a roça e o engenho: Roceiros e Fazendeiros em Minas Gerais, primeira metade do século XIX. Editora Viçosa. Universidade Federal de Viçosa. 2008. 
as conclusões de João Fragoso acerca da autonomia e dinamismo do mercado interno.

Podemos afirmar que os veios comuns dessas duas dissertações marcaram a historiografia econômica de Minas Gerais e motivaram outros pesquisadores a elaborar problemas de pesquisa sobre a plataforma que ali estaria sendo consolidada: a caracterização da estrutura produtiva, do comércio interno (sobretudo o de alimentos), do uso do trabalho escravo, entre outros.

Por este caminho chegamos ao trabalho de Sônia Maria de Magalhães, também ex-aluna da Universidade Federal de Ouro Preto, que defendeu dissertação de mestrado em 1998 na Universidade Estadual Paulista (UNESP). "A mesa de Mariana: produção e consumo de alimentos em Minas Gerais (1750-1850)", ${ }^{17}$ aborda as práticas alimentares em Minas Gerais, tendo também Mariana, como objeto de análise. Apesar da proposta de penetrar no cotidiano e nas práticas religiosas dos mineiros que permeiam a alimentação, a autora dedica parte importante do texto final a situar o tema no espectro da estrutura econômica, produtiva e no comércio da região.

Sônia Magalhães apóia-se na renovação historiográfica acerca da economia da mineração, que verificou co-existência entre extração do ouro e agropecuária desde o século XVIII. O alvorecer do século XIX foi caracterizado pela consolidação do comércio de produtos agropecuários, sendo os espaços urbanos, como a vila sede de Mariana, centralizadores de serviços administrativos, os principais consumidores. A ideia de manutenção, nos cem anos de análise, de uma estrutura produtiva que, apesar das conjunturas não se altera, é claramente baseada na periodização e resultados da pesquisa de Carla Almeida. Essa estrutura produtiva,

\footnotetext{
${ }^{17}$ MAGAlHÃES, Sônia Maria de. A mesa de Mariana: produção e consumo de alimentos em Minas Gerais (1750-1850). Dissertação (Mestrado em História). Universidade Estadual Paulista (UNESP). Franca. 1998. Este trabalho foi publicado em 2004: MAGALHÃES, Sônia Maria de. A mesa de Mariana: produção e consumo de alimentos em Minas Gerais (1750-1850). São Paulo. Annablume. Fapesp. 2004
} 
calcada na diversificação de culturas, seria fundamental para a subsistência regional, uma vez que os produtos reinóis, eram de acesso restritos à mesas mais abastadas. Aqui entram na análise as freguesias e distritos estudados por Francisco Andrade, onde se praticava a produção extensiva com abertura de matas virgens, por "roceiros e fazendeiros", contradição símbolo das desigualdades do espaço rural mineiro.

Reparemos o quanto a renovação da história econômica de Minas Gerais teve importância para o tema de pesquisa de Sônia Magalhães. Os pressupostos de uma economia estagnada e subsistente não dariam origem a uma abordagem que alia produção, comércio e consumo de alimentos. Mais uma vez vemos emergir de um debate historiográfico amplo uma análise local, comprometida com o embasamento empírico. Sônia Magalhães analisou a literatura de viagem, 300 inventários post-mortem (em seus bens móveis e utensílios) e principalmente os livros de contas do Seminário Nossa Senhora da Boa Morte. As perguntas fundamentais eram: o que se comia, como se comia e qual a manutenção ou mudança dessas práticas no tempo.

A alimentação básica dos mineiros era o milho e seus derivados, feijão, arroz, as carnes suína e bovina. Esse conjunto variava com o acréscimo de hortaliças, frutas, legumes, carne de galinha ou de peixe, mas não se alterou muito no tempo e nem se modificava, em termos qualitativos, entre as mesas de pobres e famílias abastadas. Talvez ricos e pobres se diferenciavam mais pela quantidade de comida à mesa do que pela distinção dos pratos. O consumo de importados (ou produtos reinóis) era privilégio de poucas famílias e, é claro, de religiosos, entre os quais os alunos do Seminário. Através dos inventários post mortem foi possivel verificar os utensílios da mesa. Mais uma vez, a sofisticação não era a regra e praticamente nada se alterou no tempo da análise. Incluase, aí, os modos dos mineiros, ricos ou pobres, que pareciam vorazes comilões aos olhos dos viajantes.

Apesar de boa parte da documentação analisada por Magalhães ser remanescente do século XIX, a autora trabalha 
com a ideia de manutenção no tempo tanto de uma estrutura econômica quanto das práticas sociais alimentares, variando talvez nos momentos de maior ou menor abundância.

\section{Do Regional para o Local}

Passadas as décadas de 1980 e 1990, quando havia esquentado o debate acerca da economia colonial e, no caso de Minas Gerais, sobre o pós-auge da mineração, outras pesquisas surgiram trazendo algo em comum: utilizar-se de recortes locais, ainda menores, para responder à questões gerais da historiografia. Do mesmo modo, novos pesquisadores lançaram mão de variados complexos documentais e de pressupostos metodológicos complementares à seriação, quantificação e recortes longos, como os vistos nos trabalhos apresentados até aqui.

É o caso de Camila Carolina Flausino, também graduada na Universidade Federal de Ouro Preto, onde havia tido contato com o tema do tráfico interno de escravos. A autora indagava-se de como a documentação existente em Mariana poderia contribuir para o debate que Roberto Martins levantou mais de duas décadas atrás: as regiões não exportadoras de Minas Gerais tiveram capacidade econômica de importar escravos africanos e a região da emergente cultura cafeeira no século XIX, a Zona da Mata, não teria absorvido o contingente escravo perdido pelos centros mineradores. ${ }^{18}$ Afirmação que contrariava as antigas teses da decadência mineira no bojo do esvaziamento dos veios auriferos. Com este tema, em 2006, fora defendida dissertação de mestrado na Universidade Federal de Juiz de Fora, sob o título, "Negócios da escravidão: tráfico interno de escravos em Mariana, 1850$1886 " .{ }^{19}$

\footnotetext{
${ }^{18}$ MARTINS, Roberto. "Minas Gerais e o apego à escravidão numa economia não exportadora”. Estudos Econômicos. Vol 18. N. 3 São Paulo 1983.

${ }^{19}$ FLAUSINO, Camila Carolina. Negócios da escravidão: Tráfico interno de escravos em Mariana, 1850-1886. Dissertação (Mestrado em História). Instituto de Ciências Humanas. UFJF. Juiz de Fora. 2006.
} 
O termo de Mariana, agora na segunda metade do século XIX, portanto, após o fim do tráfico atlântico de escravos, aparece como espaço da abordagem de Camila Flausino, a partir de um panorama da história econômica de Minas Gerais e da própria cidade. Entre as referências da autora está o trabalho de Carla Almeida, mas também outra dissertação sobre reprodução e famílias escravas em Mariana, entre 1850-1888, defendida na Universidade de São Paulo em 2001, por Heloísa Teixeira. ${ }^{20}$

Nas 353 escrituras de compra e venda foram computados 701 escravos. Essa documentação foi exaustivamente dissecada para que a autora testasse as teses referentes ao comércio interno de cativos, ou seja, se "teriam ocorrido transferências significativas de escravos da região de Mariana para outras regiões mais dinamizadas da província e mesmo fora dela, como [por exemplo], a Zona da Mata [cafeeira]" .$^{21}$ A divisão espacial da origem e destino dos escravos descritos nas transações foi importante para distinguir: Mariana (centro), freguesias (do próprio termo de Mariana) e Zona da Mata (região cafeeira). A autora conclui com esta análise que a maior parte das transações ocorriam dentro do município de Mariana ou com municípios da região Metalúrgica Mantiqueira, o que atacaria a ideia de que houve migração da mãode-obra cativa para a expansão cafeeira. Assim, as compras e vendas registradas no cartório de Mariana, centro urbano que, de fato, perdeu cativos no período, não sinalizavam como destino tais regiões economicamente mais dinâmicas, as exportadoras.

A lógica de interpretação dos dados e os próprios resultados da análise empírica são tributários da ideia, que hoje parece dominante, de potencial de acumulação na cadeia produtiva e comercial do mercado interno. Se há dinamismo interno, há acumulação, isto quer dizer que existem pessoas, muito provavelmente membros da elite local, que dão vida e

\footnotetext{
${ }^{20}$ TEIXEIRA, Heloísa Maria. Reprodução e Famílias escravas em Mariana. 18501888. Dissertação (Mestrado em História). USP. São Paulo 2001.

${ }^{21}$ FLAUSINO, Camila. Op cit. 2006. p 16.

224 Revista de História Regional 15(2): 211-234, Inverno, 2010
} 
operam estratégias de enriquecimento e também de poder e prestígio. Este caminho de abordagem tem figurado em análises atuais sobre a história de Minas Gerais, sobretudo do século XVIII e XIX, que aliam reprodução econômica, inserção social e papel político de sujeitos históricos.

No último capítulo de "Negócios da escravidão", Camila Flausino leva a cabo um diálogo inicial com este modelo de abordagem e traça a trajetória social, política e familiar de 4 dos principais negociantes de escravos de Mariana. Fazendo menção à referências teórico-metodológicas como a prosopografia e a microhistória italiana, a autora percebe como esses negociantes se inseriam na sociedade dos chamados "principais da terra" e se utilizavam dessas posições na busca de prestígio e também vantagens.

Podemos observar claramente uma aliança entre uma tradição historiográfica econômica, com minucioso trabalho de quantificação e seriação com uma nova abordagem, mais qualitativa e com maior presença de indivíduos e suas redes de relações sociais. Além da influência nítida da dissertação de mestrado de Carla Almeida em todos os trabalhos até aqui analisados, a tese de doutoramento da mesma autora, defendida em 2001, sobre a elite colonial mineira, também marca influência, na medida em que propõe essa relação da tradição serial com a microanálise. ${ }^{22}$

Aproximando-se desse modelo, Luís Henrique de Oliveira, graduado na Universidade Federal de Ouro Preto, defendeu sua dissertação de mestrado ${ }^{23}$. O trabalho teve por objeto o perfil dos proprietários, homens livres pobres, denominados "camponeses", em uma das freguesias de Mariana, Guarapiranga. O povoado, localizado na região da Zona da Mata, desde o século XVIII desenvolveu atividades

\footnotetext{
${ }^{22}$ ALMEIDA, Carla Maria de Carvalho. Homens ricos, homens bons: Produção e hierarquização social em Minas Colonial: 1750-1822. Tese (Doutorado em História). Instituto de Ciências Humanas e Filosofia. UFF. Niterói. 2001.

${ }^{23}$ OLIVEIRA, Luís Henrique. Nas malhas da incerteza: comportamento camponês e estratégias camponesas na freguesia de Guarapiranga (1750-1820). Dissertação (Mestrado em História). Instituto de Ciências Humanas. UFJF. Juiz de Fora. 2006.
} 
mineradoras e agropecuárias. O autor limitou-se a um recorte que não ultrapassasse o período colonial, mas, a exemplo de Carla Almeida percebeu a manutenção, no tempo, de características estruturais da economia mineira.

Mesmo em uma sociedade escravista, nem todos os livres possuíam escravos. No caso do Brasil, a possibilidade de aquisição de um cativo variou de região e do período em análise. Os camponeses estudados por Luís Henrique de Oliveira eram pequenos proprietários de escravos, de terras e que lançavam mão de estratégias de sobrevivência e diferenciação social. A opção por utilizar o termo "camponês" para a economia mineira advém de um grande panorama da historiografia que trata do tema dos proprietários livres que se utilizam, predominantemente do trabalho familiar para a sobrevivência da unidade econômica doméstica.

Ao se utilizar da quantificação de dados extraídos de amostra decenal de inventários post-mortem, a pesquisa repete a metodologia da dissertação e tese de doutoramento de Carla Almeida, ambas já citadas: encontrar característica produtiva, faixas de fortuna, posse da terra e de escravos. Dessa forma, muito do que já se sabia sobre a elite econômica regional também é encontrado para os chamados "camponeses" de Guarapiranga. Talvez os pontos de maior destaque do trabalho tenham sido o recorte micro-regional, aprofundando abordagem de uma freguesia, e a análise pormenorizada da propriedade escrava, ponto que o autor considera o mais polêmico para a definição do campesinato na sociedade escravista colonial.

Luís Henrique de Oliveira vale-se do critério de seleção de inventários sob a posse de 5 escravos. Este universo representaria o campesinato. A mão-de-obra cativa é considerada adicional ao trabalho familiar, significando também distinção social e segurança na dificuldade. Como $89,2 \%$ dos inventários selecionados apresentavam escravos, o autor conclui que "(...) os camponeses adquiriam escravos aptos ao trabalho, seja pela faixa etária, pelo percentual de escravos com moléstia etc, o que comprova que em Guarapiranga, o acesso à mão-de-obra escrava esteve plenamente garantido 
aos camponeses." ${ }^{24}$ Ao final, um capítulo é dedicado para seguir a trajetória de algumas famílias camponesas com o objetivo de esmiuçar o comportamento social, familiar, laços de solidariedade e destinos. Mais uma vez, o referencial da microhistória é admitido como análise qualitativa que complementa a seriação e quantificação.

A discussão do camponês na economia mineira havia sido levantada por João Fragoso, ao perceber a predominância da pequena posse de cativos pelos proprietários da agropecuária. Dessa forma, Minas figurava no mosaico das "formas não capitalistas de produção" do Centro Sul do Brasil que integrava o mercado interno, na primeira metade do século XIX. Talvez tenha sido a afirmação de Fragoso de que Minas Gerais seria uma economia camponesa, tendo o trabalho escravo como complementar, que estimulou a abordagem de Luís Henrique de Oliveira, recuando no tempo tal pressuposto.

Este tema foi objeto de pesquisa desenvolvida concomitantemente, porém com alguns pontos contraditórios. Trata-se de minha dissertação de mestrado, defendida na Universidade Federal de Minas Gerais em 2007. O trabalho intitulado, "Senhor ou Camponês? Economia e estratificação social em Minas Gerais no século XIX. Termo de Mariana. 1820-1850" também se construiu, a partir de um recorte circunscrito, em torno das grandes discussões da historiografia sobre o oitocentos mineiro. ${ }^{25}$ Aqui os problemas centrais eram a questão do estabelecimento da economia mineira como camponesa ou escravista e os critérios para definição das unidades produtivas como familiares ou dependentes da mão-de-obra cativa.

Ao estudar o termo de Mariana, optei por analisar uma freguesia, Furquim e seus distritos, região que trazia muitas das características elencadas pela historiografia para a

\footnotetext{
${ }^{24}$ OLIVEIRA, Luís Henrique. Op cit. 2006. p. 106.

${ }^{25}$ ANDRADE, Leandro Braga. Senhor ou Camponês? Economia e Estratificação social em Minas Gerais no século XIX. Mariana: 1821-1850. Dissertação (Mestrado em História). Faculdade de Filosofia e Ciências Humanas. UFMG. Belo Horizonte. 2007.
} 
economia de Minas Gerais, no pós-auge da mineração. Na contra-parte, para aprofundar de maneira mais completa o tema da estratificação social e das formas de utilização do trabalho escravo (sem o qual seria impossivel discutir o tal campesinato), comparei Furquim à porção urbana da cidade. O recorte escolhido foi o sub-período identificado por Carla Almeida como o de consolidação da economia mercantil de abastecimento (1820-1850).

Se os resultados mostraram uma economia mercantil e uma sociedade marcada por profunda hierarquização, como entre os "roceiros e fazendeiros" de Francisco Andrade, por outro lado identificaram uma verdadeira fluidez e indistinção entre as camadas pobres e médias. Assim os "roceiros" (termo utilizado por Francisco Andrade, encontrado nas fontes), escravistas ou não, ou os "camponeses" (termo utilizado por Luis Henrique de Oliveira), não teriam tido identificação social uniforme e suas características demográficas e econômicas variavam no tempo e no espaço.

Analisando listas de habitantes e inventários postmortem percebi que uma maior homogeneidade marcava o grupo de grandes escravistas, enquanto as diferenças entre os domicílios que tinham entre 3,4 ou 5 escravos e aqueles que não usavam a mão-de-obra cativa era fluída, em seus aspectos demográficos (quanto a cor, a idade, estado conjugal, sexo do proprietário etc) e econômica (quanto ao tamanho do montante de bens, estrutura produtiva e perfil da escravaria).

Essa maior heterogeneidade fora identificada pelo fato de as listas de habitantes abarcarem grande parte da população local, enquanto os inventários (fonte que exclui a população mais pobre) aprofundam apenas em parte do universo trabalhado, em geral médios e grandes proprietários. Portanto, a identificação das unidades produtivas que possuiam até 5 escravos como camponesas (ou que tem o trabalho escravo como complemento da mão-de-obra familiar) nas abordagens de Fragoso e Oliveira é relativizada, podendo, dependendo do momento da história da família, esses poucos escravos serem o principal braço e em outros serem complemento da produção doméstica.

228 Revista de História Regional 15(2): 211-234, Inverno, 2010 
Outra questão que este estudo demonstrou foi a relativa limitação dos chamados camponeses, roceiros ou pequenos proprietários, ao acesso à mão-de-obra cativa. Analisando o preço, o sexo, a idade e as condições de saúde dos cativos, percebi que este "senhor-camponês" se valia de conjunturas econômicas favoráveis ou de "peças" desvalorizados para adquirirem escravos. Portanto, grande parte de cativos, crioulos, pardos ou africanos, concentravam-se nas mãos de grandes proprietários, estes sim com potencial econômico para a renovação da sua escravaria.

Dificilmente os "camponeses" de Guarapiranga, estudados por Luis Henrique de Oliveira, guardavam diferenças fundamentais daqueles de Furquim, freguesias vizinhas, com histórico semelhante de predominância da agropecuária escravista e de uma fronteira aberta para a Zona da Mata, desde meados do século XVIII. A não ser pelo recorte cronológico, na primeira pesquisa, 1750-1822, e na segunda pesquisa, 1820-1850. Mesmo assim, a julgar pelo maior dinamismo da economia regional e da maior oferta de escravos nas primeiras décadas do XIX, tudo indica que o "senhorcamponês" teria tido maiores oportunidades neste periodo, que já mostramos serem restritas, o que não justificaria a afirmação de que no período colonial, os camponeses tiveram acesso pleno e garantido à mão-de-obra cativa.

Portanto, a julgar por uma abordagem micro-regional, estamos tratando de uma economia escravista, mercantil e hierarquizada, mas com uma complexa e fluida estratificação social entre camadas heterogêneas da sociedade. Depois de fazer essa discussão nos primeiros três capítulos, apresento o universo dos donos engenho, produtores de derivados de cana, os maiores escravistas da freguesia analisada, e o universo de comerciantes, os homens mais ricos da porção urbana da cidade. 


\section{Conclusão}

Como podemos perceber, o debate proposto em minha dissertação de mestrado, mais uma vez versa sobre temas e preocupações que foram comuns a todas as produções analisadas. Por outro lado, os problemas e lacunas que tentamos solucionar somente emergiram por causa das primeiras abordagens revisoras da história econômica de Minas Gerais e do Brasil. O comércio e o consumo de alimentos, o comércio de escravos, as desigualdades entre roceiros e fazendeiros, ou mesmo a definição e o comportamento de uma camada camponesa são temas que emergiram a partir do questionamento de que o Brasil escravista extrapolava o reduzido universo de uma economia exportadora e uma sociedade de apenas senhores e escravos.

Todo este emaranhado de temas e questões tão significativas para a historiografia brasileira, mas, sobretudo para a história de Minas Gerais, emerge da cuidadosa análise da documentação referente ao que era, pelo menos até meados do século XIX, a cidade de Mariana. Vale ressaltar a dificil tarefa de selecionar 6 dissertações, deixando de fora importantes trabalhos que tratam de economia na primeira metade do século XVIII, segunda metade do século XIX, ou de temas correlatos como administração, justiça, fiscalidade, crime, religiosidade, grupos étnicos, urbanização, campanha abolicionista, guarda nacional, política regional etc. Todos esses temas citados também utilizaram a documentação preservada sobre/em Mariana. ${ }^{26}$

\footnotetext{
${ }^{26}$ Alguns exemplos de pesquisas mais recentes que tiveram Mariana como objeto de análise: MATHIAS, Carlos L. A cor negra do ouro: circuitos mercantis e hierarquias sociais na formação da sociedade mineira setecentista, c. 1711 - c. 1756. Tese (Doutorado em História). Instituto de Filosofia e Ciências Sociais. UFRJ. Rio de Janeiro. 2009; PUFF, Flávio Rocha. Os pequenos agentes mercantis em Minas Gerais no século XVIII: Perfil, atuação e hierarquia (1716-1755). Dissertação (Mestrado em História). Instituto de Ciências Humanas. UFJF. Juiz de Fora. MG. 2007; COTA, Luís Gustavo Santos. O Sagrado Direito da Liberdade: escravidão, liberdade e abolicionismo em Ouro Preto e Mariana (1871 a 1888). Dissertação (Mestrado em História). Instituto de Ciências Humanas. UFJF. Juiz de Fora. 2007; CASTRO, Evandro Carlos Guilhon. Tropeiros em Mariana oitocentista. Dis- 
Talvez o tema da economia mineira, principalmente no bojo da renovação historiográfica sobre a crise da mineração, tenha criado uma maior fileira de análises pelo calor do debate anterior e também pela localização de Mariana que, como nenhuma outra cidade mineira, viveu o auge da mineração, urbanização, mas também da "crise" e/ou rearticulação econômica, bem como a consolidação de um complexo mercantil agropecuário.

Por outro lado, temos também uma renovação da historiografia como um todo, que passava a valorizar, desde os anos 1990, recortes regionais circunscritos, antes relegados à categoria de estudos de caso, como abordagem privilegiada para responder à questões gerais. Assim temos desde trabalhos macro-regionais como os de Douglas Libby, Transformação e trabalho em uma economia escravista. Minas Gerais, Século XIX, passando à pesquisas recortadas (o termo de Mariana), com preocupação sistêmica, como a de Carla Almeida, até chegarmos a pesquisas centradas em uma freguesia e/ou grupo específico, como a de Luiz Henrique de Oliveira.

Do ponto de vista prático da pesquisa, do processo de escolha do objeto, das fontes, do recorte temporal e espacial, das influências refletidas nessas escolhas, elementos poucas vezes expostos pelo historiador, temos a localização do Instituto de Ciências Humanas e Sociais da Universidade Federal de Ouro Preto, na cidade de Mariana. Era ali, diante da disponibilidade das fontes, "ao alcance da mão", e das discussões ocorridas no âmbito do curso de História que muitos pesquisadores (não apenas aqueles referidos neste texto) desenvolveram ideias e problemas de pesquisa que se mostraram e ainda hoje mostram fundamentais para a historiografia, sobretudo dos séculos XVIII e XIX.

Voltando às seis dissertações analisadas, seus temas de pesquisas e abordagens ainda merecem complementos.

sertação (Mestrado em História). Faculdade de Filosofia e Ciências Humanas. UFMG. Belo Horizonte 2002; SALDANHA, Flávio Henrique D. Os oficiais e o povo. A guarda Nacional em MG oitocentista, 1831 e 1850. Anablume. FAPESP. 2006. 
Apesar de algumas mudanças de tons e cores nos trabalhos mais recentes, como o recorte micro-regional, a tentativa de penetrar no universo sócio-cultural e trajetórias de famílias e indivíduos, ainda está por fazer a correlação mais direta, entre casos exemplares e ações e relações de indivíduos que, de fato, dão forma e transformam os processos sócio-econômicos, ou melhor, colorem a paisagem social. Bons exemplos de ausências que podem ser sentidas nestes trabalhos são: a de uma ponte direta e co-determinante da economia com a politica local, suas elites e classes subalternas; e, principalmente, as relações, empiricamente demonstráveis, entre o universo local e o mundo exterior. Assim teriamos uma cidade ou freguesia, não apenas como microcosmo exemplar, mas conectada ao todo, de forma variada no tempo, ou em aspectos, como politicos, comerciais e culturais.

Para tanto, parecem-me proficuas as preocupações mais recentes da historiografia em buscar nas relações sociais, não apenas materiais, de indivíduos e grupos, uma saída para a história econômica das sociedades pré-capitalistas. Alguns apontamentos sobre este modelo teórico-metodológico têm sido apresentados por João Fragoso, em artigos teóricos que refletem sobre alternativas para a história econômica. ${ }^{27}$ Obviamente, não se deve fugir à velha receita de identificação dos caracteres estruturais, buscando no recorte regional, o melhor aliado para as relações entre as instâncias micro e macro.

\footnotetext{
27 Alguns apontamentos sobre este modelo teórico-metodológico têm sido apresentados por João Fragoso: FRAGOSO, João Luís R."Alternativas metodológicas para a história econômica e social: micro-história italiana, Frederick Barth e a história econômica colonial". In.: ALMEIDA, Carla M. C. e Oliveira, Môncia Ribeiro. Nomes e números: alternativas metodológicas para a história econômica e social. Juiz de Fora. Editora UFJF.2006. p. 27-48; FRAGOSO, João Luís R. "Para que serve a história econômica? Notas sobre a história da exclusão social no Brasil". Estudos Históricos. Numero 29.FGV. Rio de Janeiro. 2002. p. 3-28. p. 4-5.
} 
Dissertando Mariana para entender o Brasil: historiografia regional ....

\section{Dissertando Mariana para entender o Brasil: historiografia regional e História econômica de Minas Gerais após o auge da mineração}

\section{Leandro Braga de Andrade}

Resumo: As transformações que ocorreram na historiografia brasileira nos anos de 1980 foram marcadas pela revisão de teses tradicionais sobre a história do Brasil, sobretudo do período escravista, mas também pela valorização das abordagens regionais. Dessa forma, seguiram-se estudos com recortes regionais que debatiam, entre outros temas, os ritmos determinantes da economia colonial/imperial. O objetivo aqui é apresentar a produção de pesquisas que, recortando a cidade de Mariana, na região central de Minas Gerais, contribuíram para o debate acerca da economia regional após o auge da mineração. E, sendo essa região fundamental para a coerência das teses que defendiam a predominância das determinações externas, ou, ao contrário, a existência de relativa autonomia interna dos ritmos da economia escravista, as referidas pesquisas trouxeram contribuições importantes para a História Econômica do Brasil. O comércio e o consumo de alimentos, o comércio de escravos, as desigualdades entre roceiros e fazendeiros, ou mesmo a definição e o comportamento de uma camada camponesa, são temas que emergiram a partir da afirmação de que o Brasil escravista extrapolava o reduzido universo de uma economia exportadora e uma sociedade de apenas senhores e escravos. Foram analisadas dissertações de mestrado que tiveram Mariana como objeto de análise, nas décadas seguintes ao auge da mineração e no século XIX.

Palavras-chave: Historiografia econômica; História regional; Minas Gerais; 
Abstract: The transformations that occurred in Brazilian historiography in the 1980s were marked by the revision of traditional theories about the history of Brazil, especially the period of slavery, but also for enhancement of regional approaches. Thus followed studies with regional sections debating, among other themes, the rhythms of the economy determinants colonial / imperial. The goal here is to present the production of research, cutting the city of Mariana, in central Minas Gerais, contributed to the debate about the regional economy after the heyday of mining. And, being a key region for the coherence of arguments that defended the predominance of external determinations or, otherwise, the existence of relative autonomy of the internal rhythms of the slave economy, these studies have brought important contributions to the Economic History of Brazil. The trade and consumption of food, the slave trade, inequalities between planters and farmers, or even the definition and behavior of a peasant layer are themes that emerged from the assertion that the slavery economy of Brazil went beyond the limited universe of an export economy and a society of masters and slaves only. Were analyzed dissertations that focused Mariana object of analysis in the decades after the heyday of mining and in the nineteenth century.

Key Words: Economic historiography; Regional history; Minas Gerais;

Recebido:03/07/2010

Aprovado: $15 / 10 / 2010$ 